\title{
Sistem Pemantau Pelanggaran Lalu Lintas Pada Traffic Light Menggunakan Sensor SRF04 Dan Kamera Berbasis Mikrokontroler AtMega8535
}

\author{
Aji Brahma Nugroho ${ }^{1}$ \\ 1,2Jurusan Teknik Elektro, Universitas Muhammadiyah Jember, Indonesia
}

\begin{abstract}
Monitoring System Traffic Violations In Traffic Light Uses SRF04 Sensor and Camera, Based Microcontroller ATmega8535 is a tool designed to facilitate the Traffic Police in a curb traffic in the area of Traffic Light. The purpose of making this tool is to minimize accidents that often happen because of many motorists who broke a red light while making the Traffic Police should not continue to maintain the traffic light area. This final report discusses the design and operation of mechanical sensor SRF04, the working principle of this device is when the red light circuit will be active, so when there is a vehicle across the finish line the red light sensor SRF04 which has been positioned on the line will send commands to the microcontroller then microcontroller instruct the camera to take pictures as much as 8 images with a gap of 1 second per 1 picture breach, the response time of the camera to the object get the average duration - mean and standard deviation of 10/19 milliseconds, and the response time of the sensor SRF04 object gets mean duration - average and a standard deviation of 43 milliseconds. The results obtained from this tool manufacture is to produce a tool that can monitor traffic automatically at traffic light.
\end{abstract}

Keywords: Microcontroller ATmega8535, SRF04, Visual Basic, Camera

\begin{tabular}{l}
\hline \hline ABSTRAK \\
\hline \hline Sistem Pemantau Pelanggaran Lalulintas Pada Traffic Light Menggunakan Sensor SRF04 dan \\
Kamera, Berbasis Mikrokontroler ATmega8535 adalah suatu alat yang di rancang untuk \\
mempermudah Polisi Lalu Lintas dalam menertibkan lalu lintas di area Traffic Light. Tujuan \\
pembuatan alat ini adalah meminimalkan kecelakaan yang sering terjadi dikarenakan banyak \\
pengendara kendaraan yang menerobos disaat lampu merah sehingga membuat Polisi Lalu Lintas \\
tidak harus terus menjaga area traffic light. Penelitian ini mendiskusikan tentang perancangan \\
mekanik dan cara kerja Sensor SRF04, prinsip kerja alat ini yaitu pada saat lampu merah rangkaian \\
akan aktif, sehingga ketika ada kendaraan yang melintasi garis batas lampu merah maka sensor \\
SRF04 yang sudah diposisikan pada garis tersebut akan mengirimkan perintah kepada mikrokontroler \\
kemudian mikrokontroler memerintahkan kamera untuk mengambil gambar sebanyak 8 gambar \\
dengan selisih waktu 1 detik per 1 gambar pelanggaran tersebut, waktu respon kamera terhadap objek \\
mendapatkan durasi rata - rata dan standar deviasi 10/19 milidetik, dan waktu respon sensor SRF04 \\
terhadap objek mendapatkan durasi rata - rata dan standar deviasi 43 milidetik. Implementasi sistem \\
menghasilkan suatu alat yang dapat memantau lalu lintas secara otomatis pada traffic light.
\end{tabular}

Kata Kunci : Mikrokontroler ATmega8535, SRF04, Visual Basic, Kamera

\section{PENDAHULUAN}

Seiring dengan perkembangan zaman yang juga disertai dengan perkembangan teknologi, jumlah kendaraan yang ada juga terus bertambah banyak, sehingga lalu lintas di jalan juga semakin bertambah padat, perkembangan tersebut membawa dampak yaitu seringnya terjadi pelanggaran dan kecelakaan lalu lintas, salah satunya yaitu pada Traffic Light. Banyaknya pengendara kendaraan yang tidak patuh pada rambu lalu lintas membuat POLANTAS ( Polisi Lalu Lintas ) menjadi benar - benar sibuk dalam mengatur ketertipan di area traffic light. Untuk itu harus ada solusi bagaimana cara agar para pengendara kendaraan akan terkena sangsi saat menerobos traffic light saat lampu merah, karena saat pengendara menerobos akan diambil gambarnya oleh kamera dan tersimpan pada komputer sebagai bukti pelanggaran.

Menurut hasil penelitian dilapangan, maka diadakannya rancangan sebuah alat Sistem Pemantau Pelanggaran Lalu Lintas pada Traffic Light menggunakan Sensor SRF04 dan Kamera berbasis Mikrokontroler 
ATmega8535. Dengan bantuan alat ini, POLANTAS akan lebih mudah mengatur lalu lintas dan juga mengurangi tingkat kecelakaan dan pelanggaran yang dilakukan para pengendara kendaraan serta meningkatkan kesadaran masyarakat dalam berkendara yang aman, tertib dan benar. Tujuan dari penelitian ini adalah merancang dan membuat alat pemantau traffic light pada lalu lintas. Adanya alat ini diharapkan dapat mengatasi kebutuhan manusia akan sistem otomatisasi khususnya pada Polisi lalu lintas.

\section{METODE PENELITIAN}

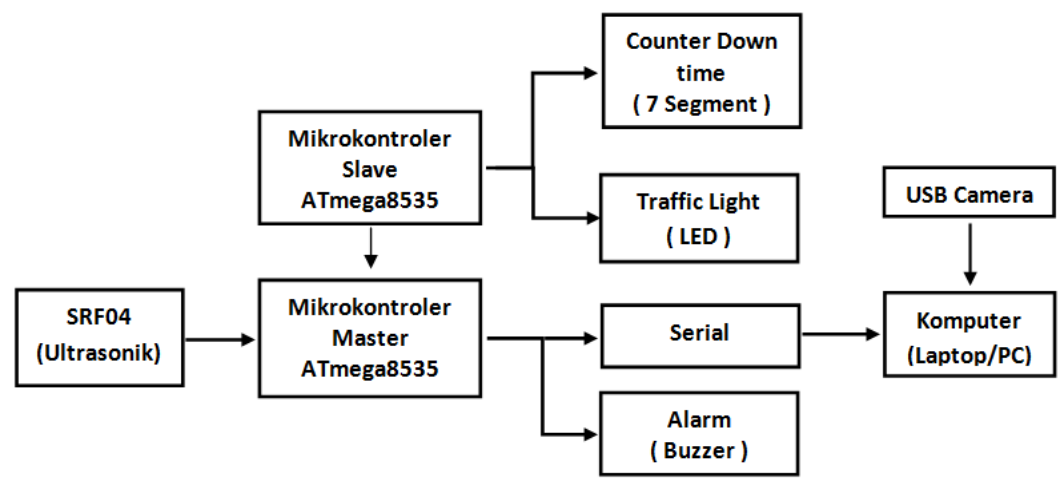

Gambar 1. Blok diagram keseluruhan system

Berdasarkan gambar blok diagram keseluruhan system seperti tampak pada Gambar 1, kami menggunakan dua Mikrokontroler Atmega8535 sebagai pengendali alat ini. Mikrokontroler 1 untuk kontrol 7 Segment dan LED, dan mikrokontroler 2 untuk Mengontrol sensor SRF04, serial dan buzzer. Cara kerja dari alat ini, mikrokontoler 1 berfungsi mengatur traffic light dan counter down timer dari 7 segment. Mikrokontroler 2 menerima input dari sensor ultrasonik dan mikrokontroler 1, kemudian mengolah data yang diterima, output dari mikrokontroler 2 adalah buzzer dan mengirim data serial ke komputer. Usb kamera terhubung ke komputer sebagai pemantau dan pengambil gambar apabila terjadi pelanggaran lalu lintas.

Rangkaian power supply berfungsi seperti tampak pada Gambar 2 berfungsi untuk mensuplay arus dan tegangan keseluruh rangkaian yang ada. Rangkaian power supply ini terdiri dari dua keluaran yaitu 5 volt dan 12 volt.

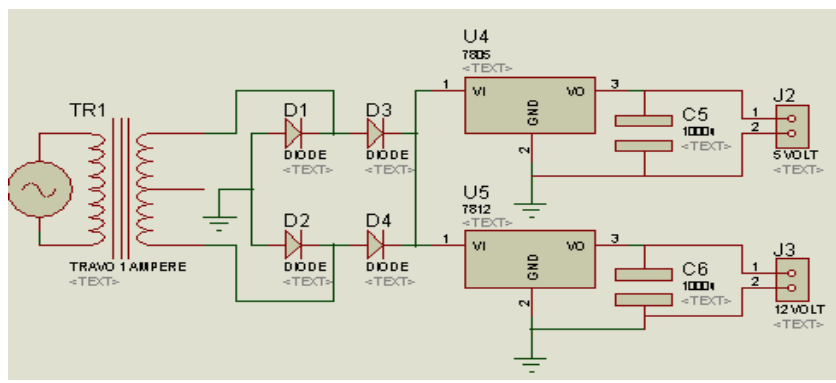

Gambar 2. Rangkaian Power Supply

Untuk pengubah level tegangan digunakan IC MAX 232. Rangkaian skematiknya tampak pada Gambar 3. IC tersebut mempunyai 2 receivers. Masing-masing berfungsi sebagai pengubah level tegangan dari level RS232 ke level Transistor Transistor Logic. Sedangkan receiver lain memiliki 2 drivers yang dapat digunakan untuk mengubah level tegangan dari level TTL ke level RS-232. Pasangan driver/receiver ini digunakan untuk TX dan RX, sedangkan pasangan yang lainnya digunakan untuk CTS dan RTS. Kapasitor diperlukan untuk pembuatan rangkaian, IC MAX 232. Kapasitor yang digunakan sebesar $1 \mu \mathrm{F}$ dengan tegangan 16 Volt pada beberapa kaki pin. Input yang diperlukan IC ini sebesar +5 Volt. 


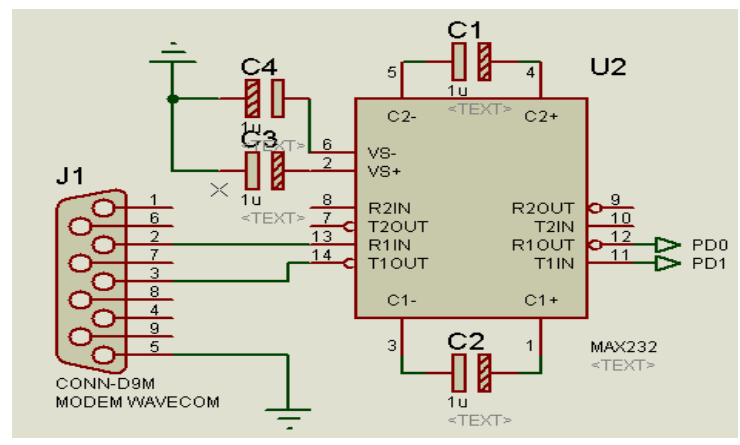

Gambar 3. Skematik untuk Pengubah Level Tegangan

\section{Pembuatan Perangkat Keras Mikrokontroler ATmega8535}

Mikrokontroler merupakan modul utama, mengunakan osilator yang terdiri dari sebuah kristal dan dua buah kapasitor. Untai ini dihubungakan dengan XTAL1 dan XTAL2, nilai kapasitor yang dipakai sebesar $20 \mathrm{pF}$ dan kristal yang digunakan mempunyai nilai $8 \mathrm{MHz}$. Reset yang direalisasikan memiliki kemampuan power-on reset, yang juga disertai dengan tombol reset, terdiri dari sebuah kapasitor, sebuah resistor dan sebuah push botton. Nilai kapasitor yang dipakai $10 \mathrm{uF}$ nilai resistor yang dipakai $10 \mathrm{~K} \Omega$.

Penggunaan pin-pin mikrokontroler slave pada perancangan sistem ini adalah sebagai berikut: PORTA digunakan untuk output 7 segment, PORTB digunakan untuk mengendalikan driver 7 segment, PORTC dan PORTD digunakan output LED, PORTD5 output ke mikrokontroler 2.

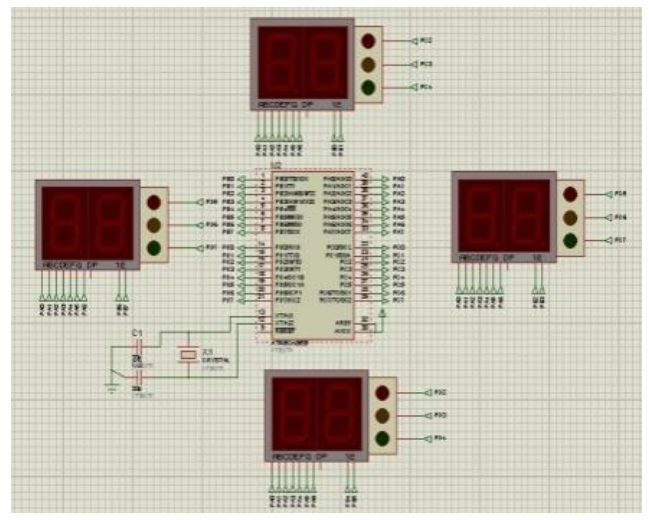

Gambar 4 Rangkaian Mikrokontroler slave ATmega 8535

\section{Pembuatan Perangkat Keras Rangkaian Driver 7 segment}

Rangkaian Driver 7 seperti tampak pada Gambar 5 berfungsi sebagai kontrol dari 8 sevent segment dan 4 lampu traffic light. Sevent segment berfungsi sebagai counter down timer traffic light sehingga pengendara dapat mengetahui dengan pasti kapan waktu berhenti dan berjalan.

\section{Perancangan Dan Pembuatan Perangkat Lunak}

Sebagai protokol antara komputer dengan mikrokontroler dibutuhkan perangkat lunak. Mode komunikasi antara komputer dengan mikrokontroler melibatkan sistem dua arah yaitu receive dan transmit ( deliver dan submit ), menggunakan jalur serial ( serial port ) dari mikrokontroler. Mikrokontroler menyesuaikan baud rate komputer, yaitu 9600 bps (bit per second). Untuk tampilan di komputer menggunakan aplikasi visual basic.

CodeVisionAVR merupakan software C- cross compiler, dimana program dapat ditulis menggunakan bahasa-C. Dengan menggunakan pemrograman bahasa-C diharapkan waktu disain akan menjadi lebih singkat. Setelah program dalam bahasa-C ditulis dan dilakukan kompilasi tidak terdapat kesalahan ( error ) maka proses download dapat dilakukan. Mikrokontroler AVR mendukung sistem download secara ISP ( In-System Programming ). 


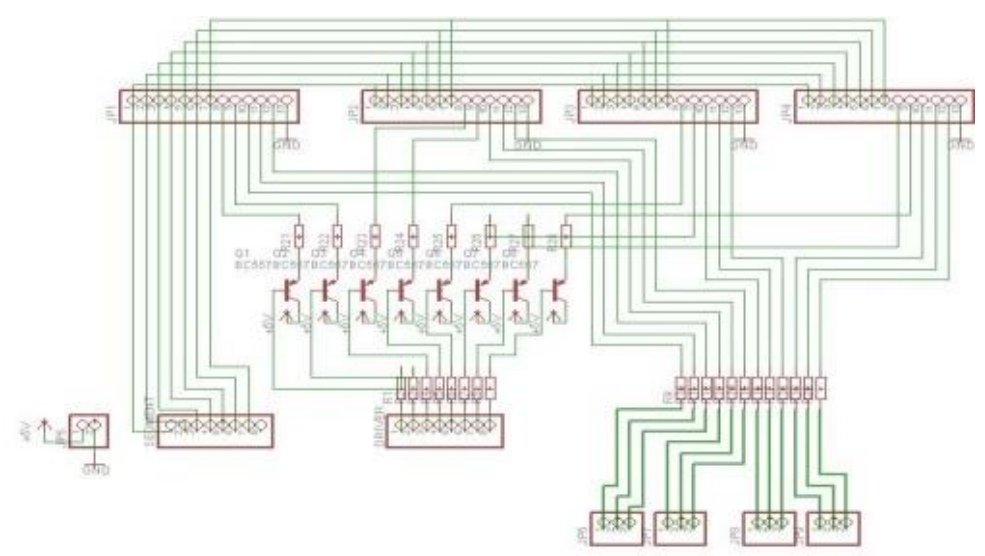

Gambar 5 Rangkaian Driver 7 Segment dan LED

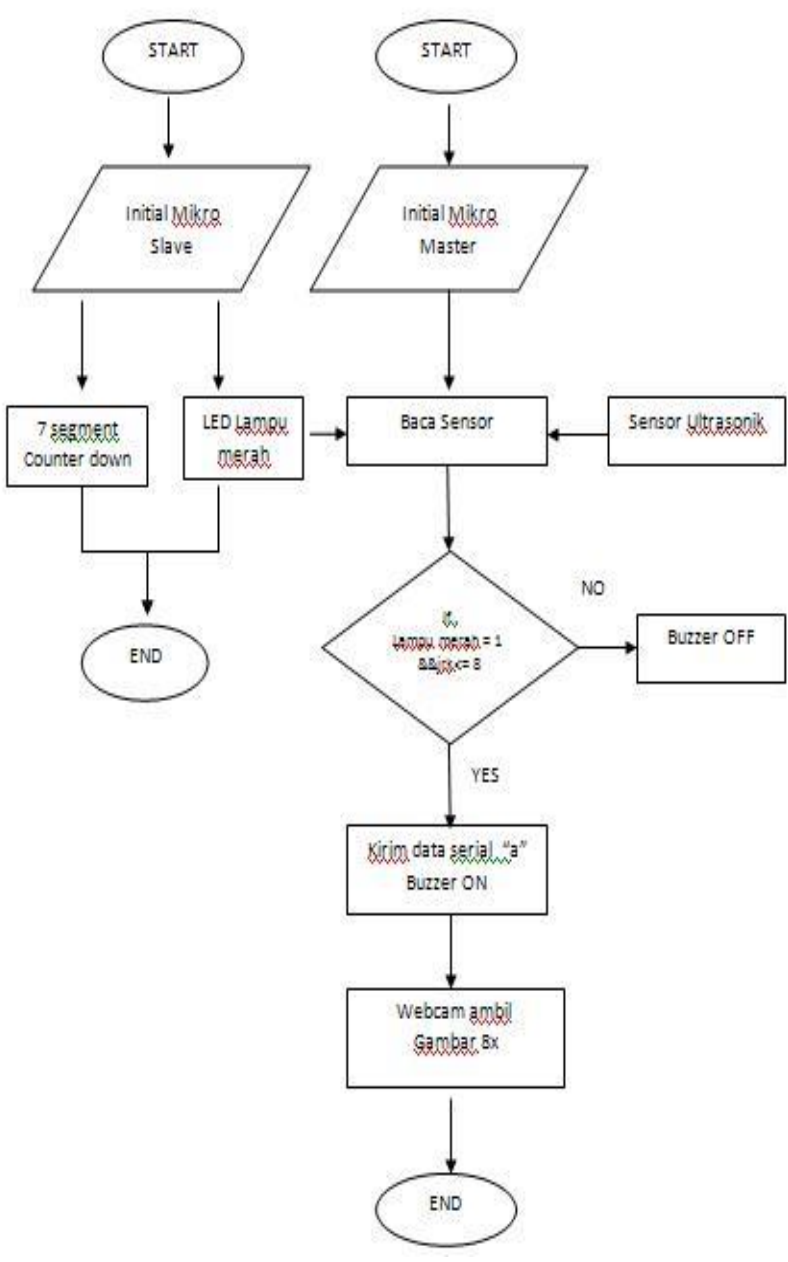

Gambar 6. Flow Chart Kontrol

\section{HASIL DAN PEMBAHASAN}

Percobaan Alat Pemantau Pelanggaran Lalu Lintas 
ELKOM “Jurnal Teknik Elektro Dan Komputasi”

Vol. 1, No. 1, Agustus 2019, Hal: 18-26

ISSN: , DOI: , Terakreditasi Dikti dengan SK:

Tabel 1. Percobaan alat pemantau pelanggaran lalu lintas

\begin{tabular}{ccc}
\hline No & Percobaan / Uji & Keterangan \\
\hline 1 & 7 Segment \& LED. & Hidup \\
\hline 2 & SRF04 \& Alarm & Mendeteksi objek \& Hidup \\
\hline 3 & Serial \& Kamera & Mengirim data \& Memfoto
\end{tabular}

Pengujian Rangkaian Seven Segment dan LED

Pengujian rangkaian Seven segment dan LED dilakukan dengan menghubungkan rangkaian driver Seven segmen ke Port B dan LED pada Port C Mikrokontroler ATmega8535 yang telah diprogram agar menghasilkan tampilan Seven Segment dan LED

Tabel 2 Pengujian Rangkaian Seven Segment dan LED

\begin{tabular}{cccccc}
\hline No & Traffic Light & Seven Segment & Port & LED & Port \\
\hline 1 & Traffic Light 1 & Hidup & B. $0 \&$ B. $1=1$ & Hijau & C. $4=1$ \\
\hline 2 & Traffic Light 2 & Hidup & B.2 \& B. $3=1$ & Merah & C. $5=0$ \\
\hline 2 & Traffic Light 3 & Hidup & B.5 \& B. $4=1$ & Merah & D. $2=0$ \\
\hline 2 & Traffic Light 4 & Hidup & B.6 \& B.7=1 & Merah & D. $5=0$ \\
\hline
\end{tabular}

Rangkaian Seven Segment dan LED bekerja dengan baik sehingga Counter down timer yang dihasilkan seven segment dan LED hidup dengan baik.

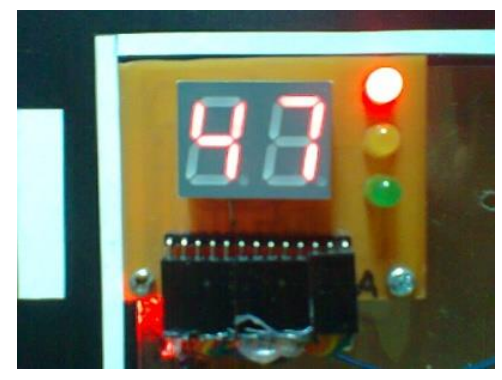

Gambar 7 Seven Segmen dan LED bekerja dengan baik

\section{Pengujian Sensor SRF04}

Untuk mengetahui apakah sensor SRF04 dapat membaca adanya pelanggaran yang terjadi saat lampu merah, maka saat objek melewati garis putih pembatas lampu merah yang berjarak maksimal $8 \mathrm{~cm}$ dari sensor SRF04, sensor akan memberi perintah kepada alarm untuk hidup dan kamera untuk mengambil gambar objek pelanggaran.

Tabel 3 Pengujian akurasi/kecepatan waktu respon sensor SRF04 terhadap objek

\begin{tabular}{ccc}
\hline No & Percobaan/uji & $\begin{array}{c}\text { Durasi } \\
\text { ( menit:detik:milidetik ) }\end{array}$ \\
\hline 1 & Ke-1 & $0: 00: 52$ \\
\hline 2 & Ke-2 & $0: 00: 56$ \\
\hline 3 & Ke-3 & $0: 00: 40$ \\
\hline 4 & Ke-4 & $0: 00: 40$ \\
\hline 5 & Ke-5 & $0: 00: 61$ \\
\hline 6 & Ke-6 & $0: 00: 45$ \\
\hline 7 & Ke-7 & $0: 00: 39$ \\
\hline 8 & Ke-8 & $0: 00: 25$ \\
\hline 9 & Ke-9 & $0: 00: 44$ \\
\hline 10 & Ke-10 & $0: 00: 45$ \\
\hline 11 & Durasi Rata-Rata & $\mathbf{0 : 0 0 : 4 3}$ \\
\hline
\end{tabular}




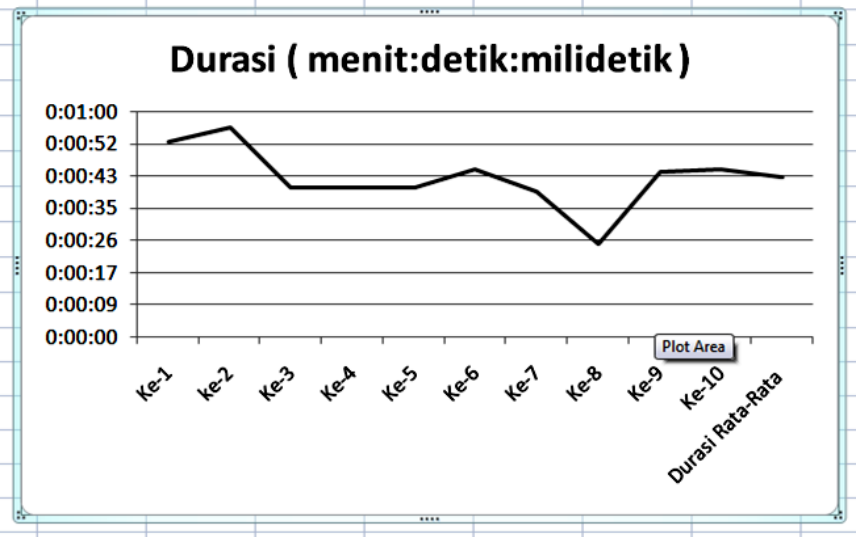

Gambar 8 Grafik akurasi/kecepatan waktu respon sensor SRF04.

\section{Pengujian Kamera}

Kamera akan bekerja mengambil gambar objek ketika ada perindah dari mikro yang dilakukan dengan mengirim data melalui komunikasi serial saat terjadi pelanggaran, pengambilan gambar dilakuakan 8 kali setiap 1 detik dan di simpan ke dalam folder berupa format jpeg sebagai data base. Pada gambar 4.2 dan gambar 4.3 akan terlihat hasil uji coba kamera saat bekerja menangkap gambar ketika terjadi pelanggaran.

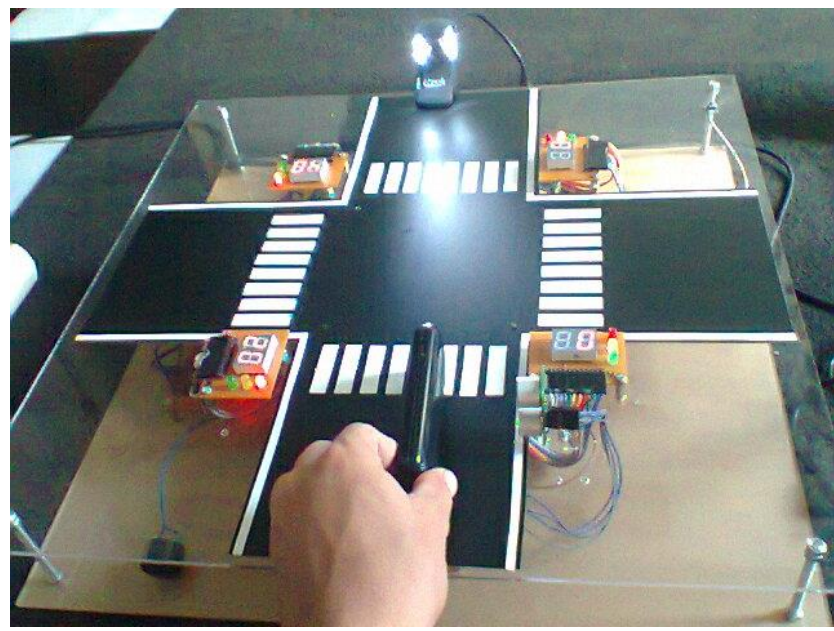

Gambar 9 Saat Kamera Mengambil Gambar Pelanggaran

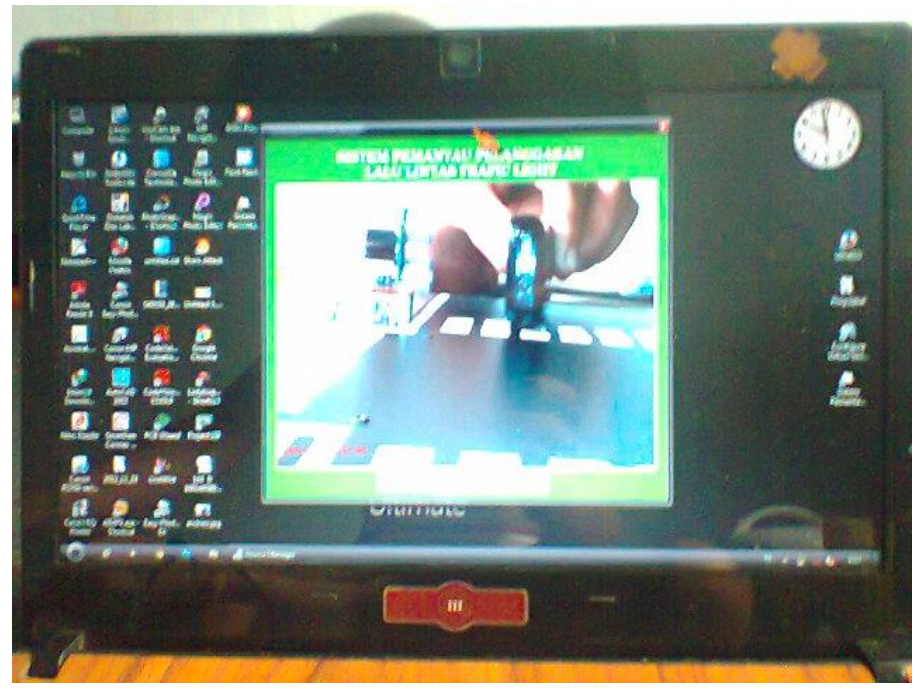

Gambar 10 Hasil Pengambilan Gambar Pelanggaran Pada Komputer 


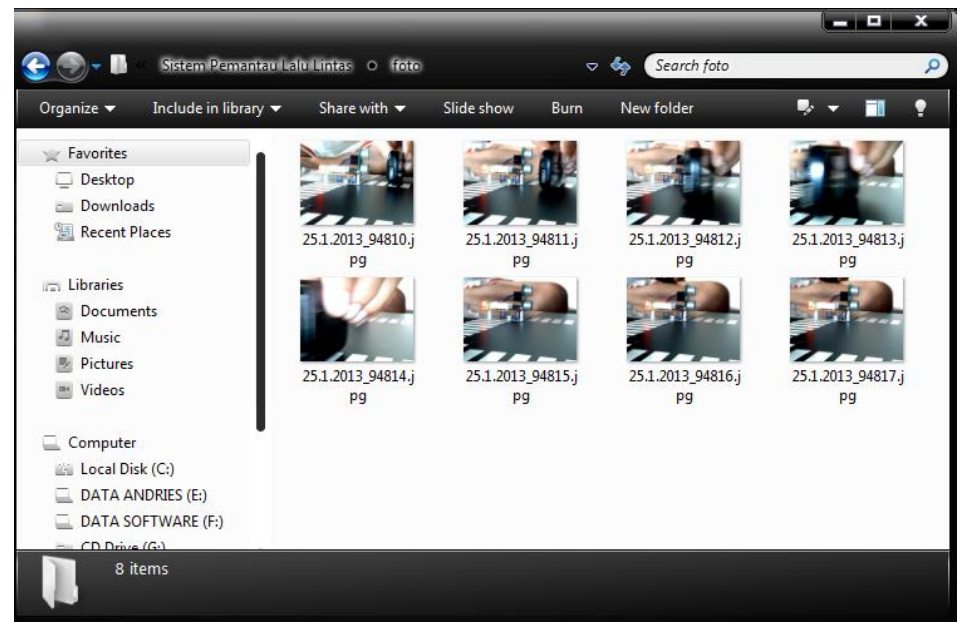

Gambar 11 Hasil Pengambilan Gambar Tersimpan Dalam Folder

Tabel 4 Pengujian akurasi/kecepatan waktu respon Kamera

\begin{tabular}{ccc}
\hline No & Percobaan/uji & $\begin{array}{c}\text { Durasi } \\
\text { ( menit:detik:milidetik ) }\end{array}$ \\
\hline 1 & Ke-1 & $0: 10: 28$ \\
\hline 2 & Ke-2 & $0: 10: 25$ \\
\hline 3 & Ke-3 & $0: 10: 13$ \\
\hline 4 & Ke-4 & $0: 10: 21$ \\
\hline 5 & Ke-5 & $0: 10: 26$ \\
\hline 6 & Ke-6 & $0: 10: 26$ \\
\hline 7 & Ke-7 & $0: 10: 16$ \\
\hline 8 & Ke-8 & $0: 10: 12$ \\
\hline 10 & Ke-9 & $0: 10: 13$ \\
\hline 11 & Ke-10 & $0: 10: 12$ \\
\hline
\end{tabular}

Dari hasil uji coba akurasi/kecepatan pada tabel 4.4, waktu respon kamera terhadap objek mendapatkan durasi rata - rata dan standar deviasi 10:19 milidetik, berdasarkan grafik di bawah ini :

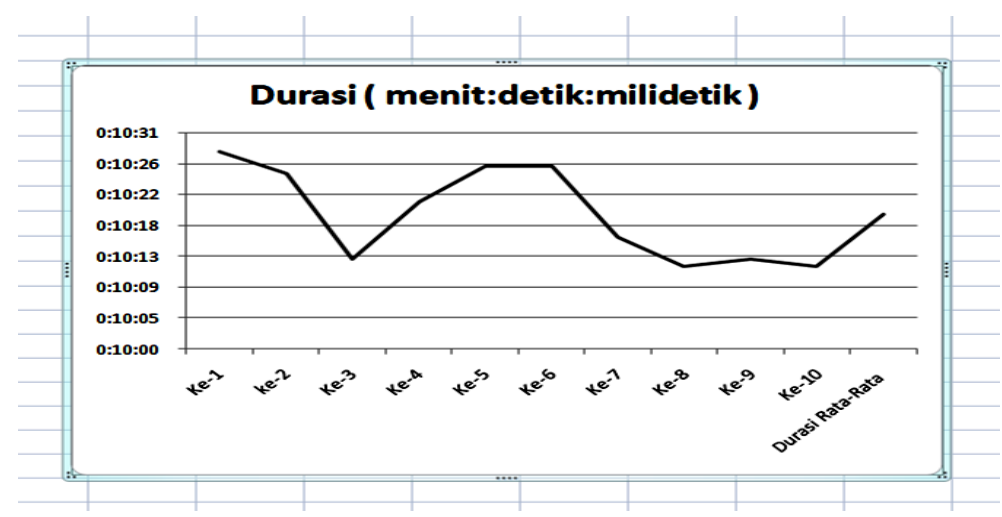

Gambar 12 Grafik akurasi/kecepatan waktu respon kamera. 


\section{Kesimpulan}

Dari hasil pengujian dan analisis yang telah dilakukan pada Sistem Pemantau Pelanggaran Lalu Lintas Pada Traffic Light Menggunakan Sensor SRF04 dan Kamera Berbasis Mikrokontroler ATmega8535, dapat disimpulkan bahwa SRF04 akan memerintah mikrokontroler untuk menghidupkan alarm dan kamera saat ada pelanggaran berupa objek yang melewati garis putih batas lampu merah yang berjarak maksimal $8 \mathrm{~cm}$ dari SRF04, Waktu respon SRF04 terhadap objek mendapatkan durasi rata - rata dan standar deviasi adalah 43 milidetik. Kamera akan mengambil gambar sebanyak 8 gambar dengan selisih waktu 1 detik per 1 gambar, dan kemudian gambar tersebut disimpan ke dalam folder berupa format jpeg sebagai data base Kepolisian. Waktu respon kamera terhadap objek mendapatkan durasi rata - rata dan standar deviasi 10/19 milidetik.

\section{REFERENSI}

[1] Affan, Muchamad, "Perancangan Dan Pembuatan Alat Pengatur Traffic Light Berbasis Mikrokontroler Untuk Deteksi Kendaraan Pemadam Kebakaran”, Teknik Telekomunikasi, Fakultas Ilmu Terapan, Universitas Telkom, 2010

[2] Muhamad Arfendi, "Rancang Bangun Model Sistem Pendeteksi Pelanggaran Lampu Merah menggunakan Infra Merah Dan Webcam", Fakultas Teknologi Industri Universitas Pembangunan Nasional "VETERAN" JATIM, Surabaya , 2011

[3] Heryato, M. Ary. Dan P. Adi, wisnu. "Pemrogaman bahasa C untuk mikrokontroler Atmega32". ANDI, Yogyakarta, 2008

[4] Winoto, Ardi.. "Mikrokontroler AVR Atmega8/32/16/8535 dan pemogramannya dengan bahasa C pada WinAVR”. Informatika, Bandung. 2008

[5] Wadhana, Lingga “Mikrokontroller AVR Seri ATMega 8535 Simulasi Hardware dan Aplikasi, Andi Yogyakarta, 2006 
ELKOM "Jurnal Teknik Elektro Dan Komputasi"

Vol. 1, No. 1, Agustus 2019, Hal: 18-26

ISSN: , DOI: , Terakreditasi Dikti dengan SK:

\section{RIWAYAT HIDUP PENULIS}

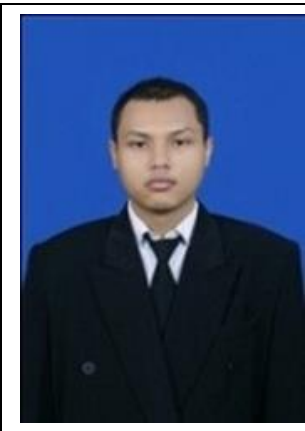

Aji Brahma Nugroho adalah dosen Program Studi Teknik Elektro Universitas Muhammadiyah Jember. Bidang penelitianny berkaitan dengan pengembangan system elektronika. 